\title{
Beyond Dual Bronchodilation - Triple Therapy, When and Why
}

\author{
Mario Cazzola $\mathbb{D}^{\prime}$ \\ Paola Rogliani $\mathbb{D}^{\prime}$ \\ Rossella Laitano' \\ Luigino Calzetta $\mathbb{D}^{2}$ \\ Maria Gabriella Matera ${ }^{3}$ \\ 'Unit of Respiratory Medicine, \\ Department of Experimental Medicine, \\ University of Rome Tor Vergata, Rome, \\ Italy; ${ }^{2}$ Unit of Respiratory Diseases and \\ Lung Function, Department of Medicine \\ and Surgery, University of Parma, Parma, \\ Italy; ${ }^{3}$ Unit of Pharmacology, Department \\ of Experimental Medicine, University of \\ Campania Luigi Vanvitelli, Naples, Italy
}

Correspondence: Mario Cazzola Email mario.cazzola@uniroma2.it

\begin{abstract}
Although pharmacological treatment of COPD is codified in different guidelines and strategy documents, there is abundant evidence of discrepancy between what they suggest and what health professionals prescribe, especially in low-risk groups where there is widespread overprescription of triple therapy. It is therefore necessary to clarify when the use of triple therapy is indicated in COPD patients and when it is preferable to maintain treatment with dual bronchodilation. In this article, we discuss our views based on our experience and what is reported in the literature and try to give answers to these two questions. The evidence generated by pivotal RCTs supports the use of triple therapy in patients who present for the first time and have severe airway obstruction, are symptomatic, have had frequent moderate or severe exacerbations in the previous year, and have peripheral eosinophilia. However, it is difficult to determine whether step-up is useful in all other cases because the available data are quite conflicting. It is likely that the inconsistency in the information generated by the various available studies may explain the prescribing behaviour of many physicians who do not adhere to recommendations of guidelines and strategies. However, it is necessary to establish whether and when the addition of an ICS to the LAMA/ LABA combination is effective, to determine whether triple therapy can induce an additional clinical benefit over dual bronchodilation, irrespective of a preventive effect on COPD exacerbations, to establish its value, and to examine whether cost differences can support the use of triple therapy over combined LAMA/LABA therapy in real life.
\end{abstract}

Keywords: dual bronchodilation, triple therapy, ICSs, LABs, LAMAs

\section{Introduction}

Growing clinical evidence suggesting that triple therapy with an inhaled corticosteroid (ICS), a long-acting $\beta_{2}$-agonist (LABA), and a long-acting muscarinic antagonist (LAMA) is effective has made it an attractive combination in COPD, but there is evidence that real-world prescribing of triple therapy does not always reflect recommendations in guidelines and strategies . ${ }^{1}$ In fact, there is proof of widespread overprescribing of such therapy, especially in lower risk groups. ${ }^{2,3}$

By using electronic health records, it was shown that in the UK 19\% of the patients classified as Global Initiative for Chronic Obstructive Lung Disease (GOLD) A (GOLD 2013 classification) and 28\% of GOLD B were prescribed triple therapy. ${ }^{4}$ In a large US claims database study, one-quarter of all treated COPD patients received such therapy. ${ }^{5}$ Among all patients who received triple therapy, approximately $75 \%$ had either mild or moderate COPD. In an Italian study, a surprising $14.08 \%$ of GOLD Group A patients were in triple therapy. ${ }^{6}$ Another extensive study of Italian patients newly diagnosed with COPD in a real-life 
context of general practitioners showed that $6.3 \%$ of patients were treated with triple therapy within the first year, and $42.3 \%$ of these patients had no prior treatment. ${ }^{7}$ Results from the Swedish National Airway Register showed that in GOLD Groups A, and B patients, $19 \%$, and 34\%, respectively, received such therapy. ${ }^{8}$

It is likely that the discrepancy between what is suggested by guidelines and strategies and what health professionals prescribe is due to the confidence physicians have in initiating comprehensive treatment to ensure the best therapy for their patients. ${ }^{9}$ Nevertheless, it remains surprising that many general practitioners prescribe triple therapy shortly after or even before an established COPD diagnosis. $^{10,11}$ Variables associated with ICS/LABA/ LAMA therapy initiation in newly diagnosed patients with COPD were $\mathrm{FEV}_{1}$, exacerbations, male sex, increased age, current or previous smoking, and some comorbid lung conditions in $\mathrm{US}^{10}$ and male sex, older age, previous exacerbations, asthma-COPD overlap, a previous treatment regimen containing an ICS, previous pneumonia, and history of lung cancer in Spain. ${ }^{11}$ However, the transition to triple therapy in those already on regular treatment for COPD, which is not necessarily a LABA/LAMA combination, follows pathways that are influenced by many different factors that vary both within and between countries probably due to differences in prescribing practices. ${ }^{12}$

In this article, we aim to discuss our views on when the use of triple therapy is really indicated in patients with COPD and when it is preferable not to go beyond dual bronchodilation.

\section{Triple Therapy in Guidelines and Treatment Strategies}

Treatment of COPD is codified in the recommendations of the GOLD strategy. ${ }^{13}$ Triple therapy with ICS/LABA/ LAMA should never be considered as initial drug treatment but is recommended in patients requiring further effective treatment. However, there is a substantial difference if one should aim to treat predominantly dyspnoea and exercise limitation rather than COPD exacerbations. The dyspnoea algorithm recommends escalation with the addition of a second long-acting bronchodilator, while triple therapy is recommended for patients treated with ICS/LABA who experience dyspnoea and need further treatment. Conversely, if therapy must be focused on exacerbations, triple therapy is recommended as a stepup in patients already treated with LABA/LAMA as well as in those treated with ICS/LABA. However, step-up should take place after assessment of the risk of exacerbation and, in patients treated with dual bronchodilation, after measurement of blood eosinophils to predict the likelihood of clinical benefit with ICS containing combinations.

Also, the official American Thoracic Society (ATS) clinical practical guideline, which aimed to address specific clinically important questions regarding the pharmacologic management of COPD, considered the question of whether triple therapy with ICS/LABA/LAMA is more effective and safer than dual therapy with LABA/LAMA in COPD patients who complain of dyspnoea or exercise intolerance despite the use of dual bronchodilation. ${ }^{14}$ It concluded that the benefits of triple therapy do not clearly outweigh the risks compared to dual bronchodilation in patients with COPD who have experienced zero to less than one exacerbation in the past year and suggested its use over dual therapy with LABA/LAMA in those patients with a history of one or more exacerbations in the past year that required antibiotics or oral steroids or hospitalisation.

Much more simply and pragmatically, the Canadian Thoracic Society Clinical Practice Guideline on pharmacotherapy in patients with COPD suggests that "step-up" to triple therapy should be considered for patients who remain symptomatic and have a poor health status despite being on LAMA/LABA combination therapy. ${ }^{15}$ It also adds that everyone should be assessed for the risk/benefit of adding ICS in these circumstances and, in any case, evidence of benefit from triple therapy has been demonstrated mainly in patients who have a high risk of exacerbation. Therefore, triple therapy with ICS/LABA/LAMA is recommended for patients at high risk of exacerbation despite the use of LAMA monotherapy or dual therapy (ICS/LABA or LABA/LAMA).

\section{Pharmacological and Clinical Evidence Supporting Triple Therapy} Pharmacological intervention based on the combination of a LABA with a LAMA allows the relaxation/contraction imbalance to be shifted towards a relaxed airway smooth muscle profile, which is essential in a condition of chronic airway obstruction. ${ }^{16}$ There is also a solid pharmacological rationale that supports the combination of an ICS with 
a LABA in COPD. In fact, there are bidirectional molecular interactions between corticosteroids and $\beta_{2}$-agonists that are responsible for a reciprocal enhancement of the pharmacological effects of ICS and LABA. ${ }^{17}$ Furthermore, the combination of an ICS with a LAMA can exert antiremodelling activity in addition to the well-known bronchodilating and anti-inflammatory activities of these drugs. ${ }^{17}$

Experimentally, it has been documented that an ICS/ LABA/LAMA combination can induce a synergistic bronchorelaxant effect of passively sensitised human airway smooth muscle and tissues from patients with stable COPD. ${ }^{18}$ A medium to strong synergism was detected in the small airways, while in the medium calibre bronchi the degree of synergistic interaction was consistently very strong.

Solid evidence shows that among the various combinations, the ICS/LABA/LAMA triple combination is the one that induces the strongest synergistic bronchorelaxant effect in both the middle bronchi and small airways. ${ }^{19}$ However, a translational study suggested that the synergistic interaction observed in vitro when adding a LAMA to the ICS/LABA combination may lead to maximal small airway, but not medium-calibre airway, relaxation in vivo. ${ }^{20}$ When salbutamol was administered on top of triple therapy $(2 \mathrm{~h}$ after the last inhalation of the triple combination) in severe COPD patients after two weeks of treatment, no significant improvement in peripheral resistance, expressed by the difference between resistance at 5 $\mathrm{Hz}$ (R5) and resistance at $19 \mathrm{~Hz}$ (R19) was detected whereas forced expiratory volume in $1 \mathrm{~s}\left(\mathrm{FEV}_{1}\right)$ increased significantly. The synergistic bronchorelaxant effect may improve lung hyperinflation in subjects with small airway disease and thus explain the substantial clinical benefits of triple therapy in patients with severe COPD.

It has also been shown that the mechanisms leading to the synergism caused by triple therapy are predominantly related to the genomic effect of intracellular glucocorticoid receptors and partially associated with the activation of the $\mathrm{G}_{\mathrm{s} \alpha}$ subunit $\mathrm{G}$ protein of the $\beta_{2}$-adrenoceptors ( $\beta_{2}$-ARs), which leads to the modulation of cyclic AMP-dependent protein kinase A pathway. ${ }^{18}$ However, further preclinical research is needed to assess whether the addition of a LABA/LAMA combination to an ICS can also synergistically improve the anti-inflammatory effect of the ICS itself.

To date, several meta-analyses tried to define the role of triple therapy in the treatment of COPD. ${ }^{21-27}$ Overall, they showed that triple therapy with ICS/LABA/LAMA provides modest clinical benefit in the general COPD population, but in patients on LABA/LAMA combination therapy, who still experience exacerbations of COPD and have blood eosinophil counts $\geq 300$ eosinofili $\cdot \mu \mathrm{L}^{-1}$ it is of clinical relevance. ${ }^{28}$ Table 1 shows the pivotal RCTs in which triple therapy fixed-dose combinations (FDCs) approved for maintenance treatment of COPD were compared with dual bronchodilation.

A recent network meta-analysis aimed to directly compare triple ICS/LABA/LAMA with corresponding either dual LABA/LAMA or ICS/LABA therapies administered as FDC via the same inhaler device has provided important information on the possible positioning of triple therapy FDC in the treatment of COPD. ${ }^{29}$ It included ETHOS (Efficacy and Safety of Triple Therapy in Obstructive Lung Disease), KRONOS (A Randomized, DoubleBlind, Parallel-Group, 24-Week, Chronic-Dosing, MultiCenter Study to Assess the Efficacy and Safety of PT010, PT003, and PT009 Compared With Symbicort ${ }^{\circledR}$ Turbuhaler $^{\circledR}$ ), IMPACT (InforMing the PAthway of COPD Treatment), and TRILOGY (Single Inhaler Triple Therapy versus Inhaled Corticosteroid plus Long-Acting $\beta_{2}$ Agonist Therapy for Chronic Obstructive Pulmonary Disease) trials, the only that fulfilled the strict inclusion criteria. Application of the SUCRA (surface under the cumulative ranking curve analysis) method demonstrated that ICS/LABA/LAMA was the most effective treatment in reducing the risk of moderate to severe COPD exacerbation, followed by ICS/LABA and LABA/LAMA. This degree of efficacy was confirmed in patients with a high eosinophil count, whereas in patients with a low eosinophil count, LABA/LAMA FDC and then ICS/LABA FDC followed ICS/LABA/LAMA FDC. The improvement in $\mathrm{FEV}_{1}$ achieved the same ranking order but it appeared independent of the level of blood eosinophil count at baseline. However, ICS/LABA/LAMA was the worst treatment when the risk of pneumonia was considered, followed by ICS/LABA. The risk of pneumonia was negligible in patients treated with LABA/LAMA. The weighted efficacy/safety ratio profile resulting from SUCRA gave the following ranking: in patients with low eosinophil count, ICS/LABA/LAMA FDC > LABA/LAMA FDC 》 ICS/ LABA FDC; in patients with a high number of eosinophils, ICS/LABA/LAMA FDC > LABA/LAMA FDC > ICS/LABA FDC.

It must be mentioned that at present it is not yet known whether there are substantial pharmacological and clinical 
Table I Pivotal Trials with Triple Therapy FDCs Approved for Maintenance Treatment of COPD versus Dual Bronchodilation

\begin{tabular}{|c|c|c|c|c|}
\hline Study & Patients & Study Design & Therapy & Key Findings \\
\hline \multicolumn{5}{|c|}{ Beclomethasone dipropionate/formoterol fumarate/glycopyrronium bromide } \\
\hline TRIBUTE $^{52}$ & $\begin{array}{l}\text { Patients with a post- } \\
\text { bronchodilator } \mathrm{FEV},<50 \% \text { of } \\
\text { the predicted normal value, } \\
\geq 1 \text { moderate-to-severe } \\
\text { COPD exacerbation in the } \\
\text { previous } 12 \text { months, CAT } \\
\text { total score } \geq 10 \text { and, who had } \\
\text { used LABA/ICS, LAMA/ICS, } \\
\text { LAMA/LABA, or LAMA } \\
\text { monotherapy, but not triple } \\
\text { therapy, for at least } 2 \text { months } \\
\text { before screening }\end{array}$ & $\begin{array}{l}\text { Multicentre, randomised, } \\
\text { parallel-group, double-blind, } \\
\text { double-dummy study over } 52 \\
\text { weeks }\end{array}$ & $\begin{array}{l}\text { BDP/FF/GB } 200 / / 2 / 25 \mu \mathrm{g} \\
\text { twice daily in } 764 \text { patients } \\
\text { IND/GB } 85 / 43 \mu \mathrm{g} \text { once daily } \\
\text { in } 768 \text { patients }\end{array}$ & 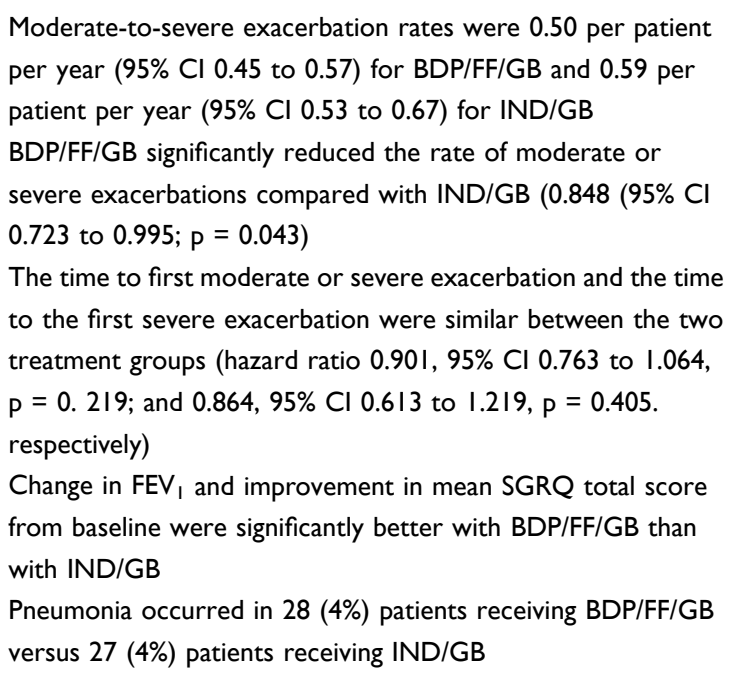 \\
\hline \multicolumn{5}{|c|}{ Fluticasone furoate/vilanterol/umeclidinium } \\
\hline IMPACT ${ }^{82}$ & $\begin{array}{l}\text { Patients with } \mathrm{FEV},<50 \% \text { of } \\
\text { the predicted normal value } \\
\text { and } \mathrm{CAT} \geq 10 \text { and } \geq 1 \\
\text { moderate or severe } \\
\text { exacerbation in the } \\
\text { previous year, or patients } \\
\text { with } \mathrm{FEV}, \geq 50-<80 \% \text { and } \\
\mathrm{CAT} \geq 10 \text {, and } \geq 2 \text { moderate } \\
\text { exacerbations in the past year } \\
\text { or } \geq 1 \text { severe exacerbation in } \\
\text { the previous year }\end{array}$ & $\begin{array}{l}\text { Multicentre, randomized, } \\
\text { double-blind, parallel-group } \\
\text { trial over } 52 \text { weeks }\end{array}$ & $\begin{array}{l}\text { FLF/VI/UMEC } 100 / 25 / 62.5 \mu \mathrm{g} \\
\text { once daily in } 425 \mathrm{I} \text { patients } \\
\mathrm{VI} / \mathrm{UMEC} 25 / 62.5 \mu \mathrm{g} \text { once } \\
\text { daily in } 2070 \text { patients }\end{array}$ & $\begin{array}{l}\text { Moderate-to-severe exacerbation rates were } 0.9 \mathrm{I} \text { per patient } \\
\text { per year for FLF/VI/UMEC, and I.2I per patient per year for VI/ } \\
\text { UMEC (rate ratio with triple therapy, } 0.75 ; 95 \% \mathrm{Cl} 0.70 \text { to } 0.8 \mathrm{I} \text {; } \\
25 \% \text { difference; } \mathrm{p}<0.00 \mathrm{I} \text { ) } \\
\text { The annual rate of moderate or severe exacerbations was } \\
\text { lower with triple therapy, regardless of eosinophil level } \\
\text { The annual rate of severe exacerbations was significantly lower } \\
\text { with triple therapy than with VI/UMEC } \\
\text { Change in } \mathrm{FEV} \text {, and improvement in mean SGRQ total score } \\
\text { from baseline were significantly better with VI/UMEC } \\
\text { The risk of clinician-diagnosed pneumonia was significantly } \\
\text { higher with FLF/VI/UMEC than with VI/UMEC, as assessed in } \\
\text { a time-to-first event analysis (hazard ratio, I.53; } 95 \% \mathrm{CI}, \mathrm{I} .22 \text { to } \\
\text { I.92; } \mathrm{P}<0.00 \mathrm{I} \text { ) }\end{array}$ \\
\hline
\end{tabular}




\begin{tabular}{|c|c|c|c|c|}
\hline \multicolumn{5}{|c|}{ Budesonide/formoterol fumarate/glycopyrronium bromide } \\
\hline $\mathrm{KRONOS}^{83}$ & $\begin{array}{l}\text { Patients with post- } \\
\text { bronchodilator } \mathrm{FEV}, \geq 25- \\
<80 \% \text { of the predicted normal } \\
\text { value, and CAT } \geq 10 \text { despite } \\
\text { receiving two or more inhaled } \\
\text { maintenance therapies for at } \\
\text { least } 6 \text { weeks before } \\
\text { screening }\end{array}$ & $\begin{array}{l}\text { Multicentre, randomised, } \\
\text { double-blind, parallel-group } \\
\text { trial over } 24 \text { weeks }\end{array}$ & $\begin{array}{l}\text { BUD/FF/GB } 320 / 9.6 / 18 \mu \mathrm{g} \\
\text { twice daily in } 640 \text { patients } \\
\text { FF/GB } 9.6 / 18 \mu \mathrm{g} \text { twice daily in } \\
627 \text { patients }\end{array}$ & $\begin{array}{l}\text { BUD/FF/GB did not significantly improve morning pre-dose } \\
\text { trough FEV at week } 24 \text { versus FF/GB (I3 mL, }-9 \text { to } 36 \mathrm{~mL} \text {; } \\
\mathrm{p}=0.2375 \text { ) } \\
\text { BUD/FF/GB resulted in nominally significant improvements in } \\
\text { SGRQ total score but not TDI focal score over } 24 \text { weeks } \\
\text { versus FF/GB } \\
\text { The rates of moderate or severe exacerbations with BUD/FF/ } \\
\text { GB were lower than with FF/GB for patients in both eosinophil } \\
\text { subgroups }\left(<150 \text { cells } / \mathrm{mm}^{3} \text { or } \geq 150 \text { cells } / \mathrm{mm}^{3}\right) \\
\text { Pneumonia incidence was low }(<2 \%) \text { and similar across } \\
\text { treatments. }\end{array}$ \\
\hline $\mathrm{ETHOS}^{51}$ & $\begin{array}{l}\text { Patients with post- } \\
\text { bronchodilator } \mathrm{FEV}_{1} \geq 25 \text { - } \\
<65 \% \text { of the predicted normal } \\
\text { value, CAT } \geq 10 \text { and history of } \\
\text { at least one moderate or } \\
\text { severe COPD exacerbation } \\
\text { (if their } \mathrm{FEV} \text {, was }<50 \% \text { of the } \\
\text { predicted normal value) or at } \\
\text { least two moderate or at least } \\
\text { one severe COPD } \\
\text { exacerbation (if their } \mathrm{FEV}, \\
\text { was } \geq 50 \% \text { of the predicted } \\
\text { normal value) in the year } \\
\text { before screening }\end{array}$ & $\begin{array}{l}\text { Multicentre, randomized, } \\
\text { double-blind, parallel-group } \\
\text { trial over } 52 \text { weeks }\end{array}$ & 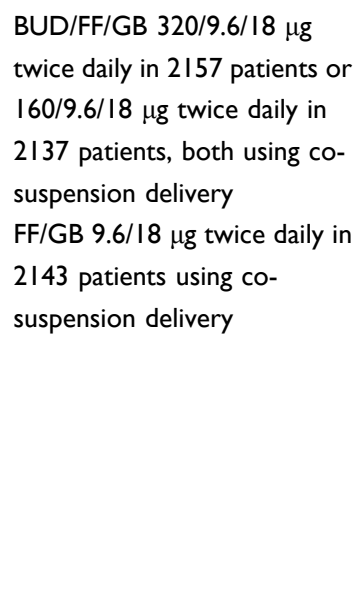 & $\begin{array}{l}\text { The annual rates of moderate or severe exacerbations were } \\
1.08 \text { with BUD/FF/GB } 320 / 9.6 / 18 \mu \mathrm{g}, 1.07 \mathrm{BUD} / \mathrm{FF} / \mathrm{GB} 160 / 9.6 / \\
18 \mu \mathrm{g}, \mathrm{I.42} \text { with FF/GB } \\
\text { Both triple-therapy regimens significantly prolonged the time to } \\
\text { the first moderate or severe exacerbation as compared with } \\
\mathrm{FF} / \mathrm{GB} \\
\text { The incidence of confirmed pneumonia was } 3.5 \% \text { with BUD/FF/ } \\
\mathrm{GB} 160 / 9.6 / 18 \mu \mathrm{g}, 4.5 \% \text { with BUD/FF/GB } 320 / 9.6 / 18 \mu \mathrm{g} \text { and } \\
2.3 \% \text { with } \mathrm{FF} / \mathrm{GB}\end{array}$ \\
\hline
\end{tabular}

Abbreviations: BDP, beclomethasone dipropionate; BUD, budesonide; CAT, COPD assessment test; FEV, forced expiratory volume in I second; FF, formoterol fumarate; FLF, fluticasone furoate; GB, glycopyrronium bromide; IND, indacaterol; SGRQ, St George's Respiratory Questionnaire; TDI, transition dyspnea index; UMEC, umeclidinium; VI, vilanterol. 
differences between the various ICS/LABA/LAMA FDCs available or in development. In fact, head-to-head trials comparing the different triple therapies have not yet been performed. However, the composition of each FDC differs from the others in terms of the pharmacodynamic and pharmacokinetic characteristics of its molecules, and the drug delivery device that it uses (Table 2).

ICSs approved for clinical use exhibit a range of glucocorticoid receptor selectivity, potency, physicochemical properties, and pharmacokinetic parameters. ${ }^{30,31}$ More potent molecules can be administered at much lower doses to achieve similar clinical efficacy. Among the approved ICSs, flunisolide is the least and fluticasone furoate the most potent. Lipophilicity is also very important because it results in slower dissolution and pulmonary absorption of inhaled drug particles with longer retention times in the airways, longer duration of action, and the possibility of less frequent dosing. The following order of pulmonary retention times has been reported: fluticasone furoate $\gg$ mometasone furoate $\geq$ fluticasone propionate $>$ triamcinolone acetonide $\gg$ budesonide $\geq$ desisobutyryl ciclesonide $>$ flunisolide $\geq$ beclomethasone dipropionate. More potent ICSs as well exhibit greater binding to plasma proteins in the systemic circulation and thus are not available for binding to extrapulmonary glucocorticoid receptors, limiting the possibility of systemic side effects. Also very important is the relationship between the terminal half-lives after inhalation and the elimination half-lives after intravenous administration of the various ICSs because a terminal half-life after inhalation that is greater than that after intravenous administration may reflect slow absorption from lung tissue. Differences in dissolution rates affect the time to reach the maximum plasma concentration, and the area under the time profile of the plasma concentration. An ICS with a long half-life but present at low plasma concentrations may have a better safety profile than an ICS with a shorter half-life that is present at high concentrations.

LABAs differ substantially in key pharmacological parameters, such as selectivity for and residence time on the $\beta_{2}$-AR, potency, intrinsic efficacy (namely the extent to which they activate the receptor), and lipophilicity. ${ }^{32,33}$ These differences are critical in characterizing the pharmacological profile (primarily the onset and duration of action, but also the loss of responsiveness to chronic LABA therapy) and, consequently, the clinical effect of each LABA. It should be noted, however, that apparently, slow receptor dissociation is not a key factor in the duration of action of LABAs whereas partitioning of the drug into lipophilic compartments after inhalation is the key determinant of their long duration of action. LABAs with high intrinsic efficacy, ie, full, or nearly full agonists, such as formoterol, indacaterol, or olodaterol may cause greater loss of $\beta_{2}$-ARs than low efficacy agonists, or partial agonists, such as salmeterol or vilanterol, but need to activate a lower number of $\beta_{2}$-ARs, ie, they induce the same maximal response occupying fewer $\beta_{2}$-ARs than partial agonists to cause a given ASM relaxant effect. However, it is possible that partial agonists could provide greater benefit for the treatment of COPD by minimizing overstimulation and desensitization of $\beta_{2}$-ARs surface cells than full agonists.

Regarding LAMAs, there are substantial differences in their pharmacological profiles. ${ }^{33,34}$ Their onset of action probably differs somewhat in the different time taken to reach equilibrium at the $M_{3} \mathrm{mAChR}$. Their offsets of action duration and potency also differ significantly. The documentation that glycopyrronium has a shorter residence time at the $\mathrm{M}_{3} \mathrm{mAChR}$ than other LAMAs but is effective even if administered once daily suggests that other underlying processes within the airway could contribute. In any case, a translational study has shown that doses of LAMA approved for the treatment of COPD are not delivered into the lung at iso-effective concentrations. $^{35}$

In any case, in the absence of direct comparisons, a recent systematic review of the literature and a network meta-analysis found that there was no substantial difference between budesonide/formoterol/glycopyrronium 320/ 9.6/18 $\mu \mathrm{g}$ twice daily, beclomethasone dipropionate/formoterol/glycopyrronium 200/12/25 $\mu \mathrm{g}$ twice daily, and fluticasone furoate/vilanterol/umeclidinium 100/25/62.5 $\mu \mathrm{g}$ once daily regarding reduction in exacerbation rates and use of rescue medications, and improvement in lung function, quality of life, and symptoms at or over 24 and 52 weeks. $^{36}$

\section{Blood Eosinophil Count as a Biomarker for the Use of Triple Therapy}

Since meta-analyses also indicated that the protective effect of triple therapy against the risk of moderate or severe COPD exacerbations was greater in patients with a high number of eosinophils in blood, it is worth clarifying the role of increased blood eosinophil count as 
Table 2 Pharmacological Characteristics of the ICSs, LABAs and LAMAs Included in Triple Therapy FDCs Approved for Maintenance Treatment of COPD

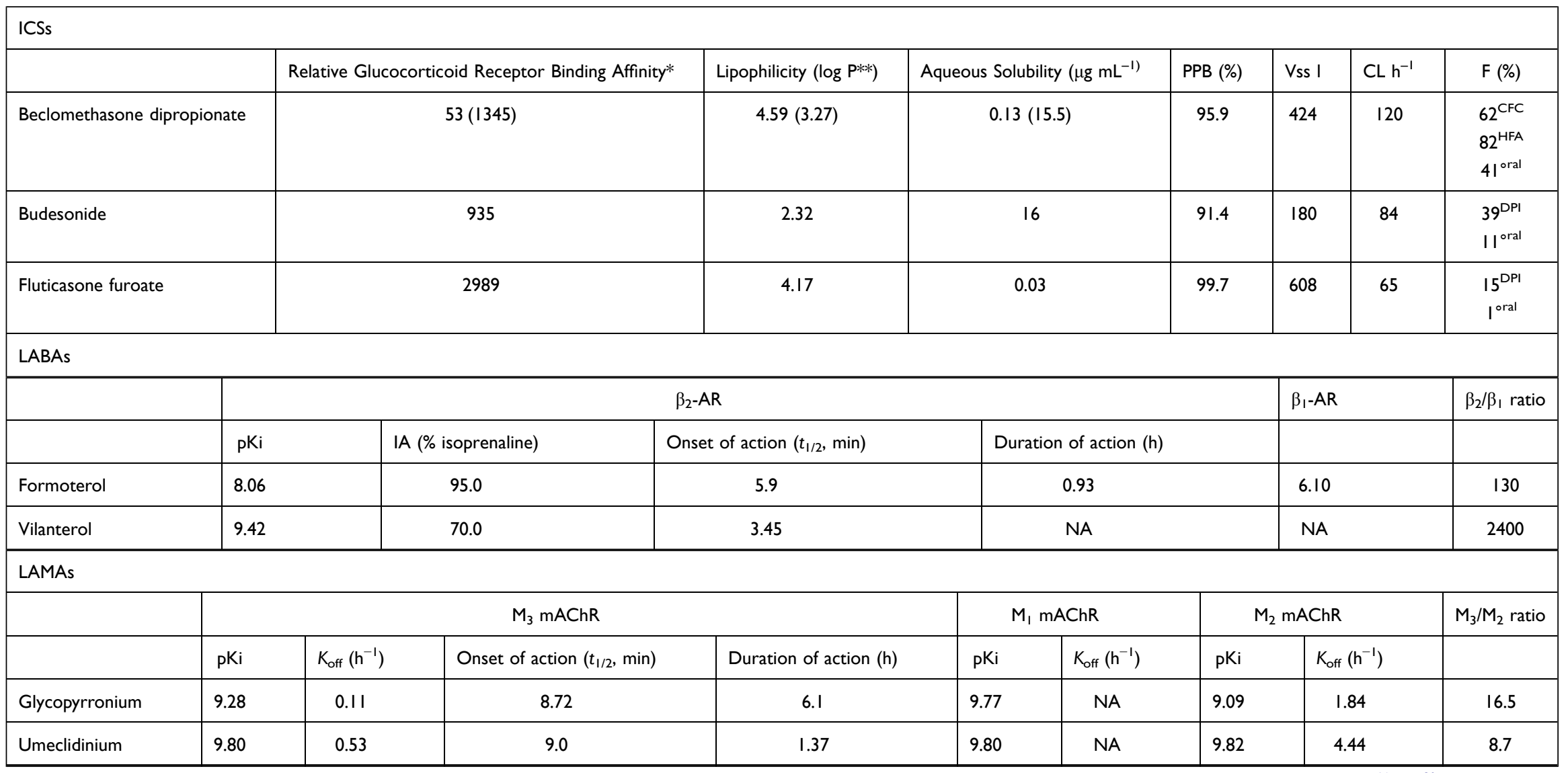

Notes: ${ }^{*}$ Glucocorticoid receptor binding affinity is relative to dexamethasone with dexamethasone affinity $=100$. ** Log $\mathrm{P}$ values are defined as the $\log _{10}$ of the octanol/water partition coefficient. Sources ${ }^{16}$ and ${ }^{30}$.

Abbreviations: $\mathrm{CL}$, plasma clearance; $\mathrm{F}$, absolute bioavailability determined in healthy subjects; IA, intrinsic activity; $K_{\text {off, }}$ dissociation rate; NA, not available in human tissue; pKi, the negative logarithm to base 10 of the equilibrium dissociation constant of a ligand determined in inhibition studies; PPB, plasma protein binding; Vss, volume of distribution at steady state; $t_{1 / 2}$, residence half-life. 
a predictive biomarker of COPD exacerbation risk and response to ICS. ${ }^{37}$

The use of cut-off thresholds for blood eosinophil counts to determine the pharmacological approach in COPD has been already recommended in the GOLD report. $^{13}$

The GOLD report gives great emphasis to the use of combinations containing ICS in patients with $\geq 300$ eosinophils $\mu \mathrm{L}^{-1}$ in the blood as this value would allow identification of patients more likely to benefit from ICS treatment, and in high-risk patients with a history of two or more moderate exacerbations or one severe exacerbation in the previous year and $>100$ eosinophils $\mu \mathrm{L}^{-1} \cdot{ }^{13}$ Patients with $<100$ eosinophils $\mu \mathrm{L}^{-1}$ in their blood should not receive ICS unless they are also asthmatic, as this value suggests that such drugs are unlikely to prevent COPD exacerbations. The real problem is the group of patients with $100-300$ eosinophils $\mu \mathrm{L}^{-1}$, for whom there is still no solid evidence to make a consistent recommendation. ${ }^{38,39}$ The decision whether to add an ICS should be based on individual considerations of likely benefits and possible risks.

Daiana Stolz and Marc Miravittles, using data of the IMPACT study, came up with an interesting scheme that can help decide the use of ICSs in COPD not only based on the number of eosinophils in the blood but also on other factors. ${ }^{40}$ According to this scheme, ICSs are indicated for the prevention of exacerbations in patients with $>300$ eosinophils $\mu \mathrm{L}^{-1}$ in blood and not indicated in those with $<100$ cells $\mu \mathrm{L}^{-1}$. For patients with blood eosinophils in the range of $100-300$ cells $\mu \mathrm{L}^{-1}$, the use of ICS may vary depending on the presence of other response-modulating factors. Being an ex-smoker, having suffered oral corticosteroid-treated exacerbations or $>2$ moderate or 1 severe exacerbations increase the response to ICSs and decrease the blood eosinophil count cut-off while being a current smoker, having suffered antibiotic-treated exacerbations or 1 or 2 moderate exacerbations decrease the response to ICSs and increase the blood eosinophil count cut-off.

We strongly believe that the step-up approach from dual bronchodilation to triple therapy proposed by the GOLD strategy and focused on the number of eosinophils in the blood does not reflect the important differences in COPD exacerbations and is therefore not tailored to the specific needs of the patient to be treated. ${ }^{28}$ In fact, COPD exacerbations are classified according to severity, which considers the use of healthcare resources, and therefore into mild, characterised by an increase in respiratory symptoms controlled by the patient with an increase in usual medication, moderate when they require treatment with systemic corticosteroids and/or antibiotics, and severe when they require hospitalisation. ${ }^{41}$ In any case, COPD exacerbations vary in frequency and in intensity. ${ }^{42}$ Furthermore, they differ in their nature, presenting a phenotypic heterogeneity with biological phenotypes characterised by different clinical biomarker. ${ }^{43}$ Sputum interleukin-1 $\beta$, serum $\mathrm{C}$-X-C motif chemokine ligand 10 , and peripheral eosinophils are biomarkers of bacteria-, virus-, or eosinophil-associated exacerbations of COPD, but there is also a pauciinflammatory phenotype.

A recent systematic review of post-hoc analyses of randomized controlled trials (RCTs) and observational studies that examined three classic blood eosinophil thresholds $\left(2 \%, 150\right.$ cells $\mu \mathrm{L}^{-1}$ and 300 cells $\left.\cdot \mu \mathrm{L}^{-1}\right)$ and the independent role of ICS showed that the strength of the positive association between ICS and the risk of COPD exacerbation was lower if the contribution of bronchodilators was excluded, and in any case of poor quality. ${ }^{44}$ Considering the results of their study, the authors concluded that data from post-hoc analyses of RCTs cannot be extrapolated to the entire COPD population and, in any case, the lack of association between ICS prescription and reduced exacerbation risk found in observational studies suggests that it may not be present within the "real world" COPD population.

Our extensive review of the literature has allowed us to reach some conclusions on the role of blood eosinophil count as a biomarker in COPD. ${ }^{45}$ First, the replicability of peripheral blood eosinophil counts is modest and, in any case, when patients are stratified into groups with persistently low, variable, and persistently high eosinophils, no significant differences in baseline characteristics are found between the groups. In addition, there is no consensus on the use of absolute or relative eosinophil counts or circulating eosinophil counts as indicator of important clinical outcomes. Another critical issue is that we still do not know whether the blood eosinophil count predicts the risk of exacerbation independently of the exacerbation phenotype and its treatment and what factors confound the interpretation of the eosinophil count. The evidence generated by several recent studies of the presence of clear differences between eosinophil populations in different patients and disease states and the phenotypic diversity of eosinophils (they may be normodense or hypodense, resident or recruited, naïve or activated) in the individual organism ${ }^{46,47}$ is another critical aspect. In fact, it is almost 
impossible to exclude that there are substantial differences between eosinophils after different interventions and between different subjects, and that there are possible associations between these differences and disease activity. For all these reasons, we believe that it is still premature to consider eosinophils as a valid biomarker in the context of COPD.

In our opinion, a more tailored approach to the patient's needs might be to try to prevent exacerbations by treating him or her according to the severity of exacerbation he or she has presented. ${ }^{48}$ If this has been mild or moderate treated with antibiotics, a treatment with LABA/ LAMA is probably most appropriate, whereas if it has been an oral corticosteroid-treated moderate exacerbation our suggested therapy is ICS/LABA. Patients who have suffered severe exacerbations should be treated with ICS/ LABA/LAMA. This view was later echoed by Vanfleteren et al who suggested that triple therapy should be considered the first choice in patients discharged from hospital after a COPD exacerbation and in those in whom COPD was first diagnosed following a severe exacerbation. ${ }^{49}$

\section{Pneumonia and Triple Therapy}

We have already mentioned that the systematic review of the literature indicates that ICS/LABA/LAMA seems to be the worst treatment when considering the risk of pneumonia, whereas this risk is negligible in patients treated with LABA/LAMA. $^{29}$

It is well known that COPD is associated with increased bacterial colonisation in the large airways, reduced macrophage phagocytosis and cytokine production. $^{50}$ These findings explain why there is a pneumonia risk in patients with COPD. However, chronic treatment with ICS further increases this risk. In fact, administration of an ICS could induce a reduction in bacterial adherence and promote the movement of bacteria to the distal airways, increasing bacterial load and modifying the respiratory microbiome, and further impair macrophage function. In such conditions, it is likely that the superimposition of a viral infection could produce additional acute impairment of host immune function, resulting in increased bacterial growth and pneumonia. ${ }^{50}$

The risk of pneumonia appears to be dependent on the dose of ICS used, as demonstrated by the ETHOS study in which budesonide $320 \mu \mathrm{g}$ BID (medium dose ICS) resulted in a higher incidence of pneumonia than budesonide $160 \mu \mathrm{g}$ BID (low dose ICS). ${ }^{51}$ In contrast, in the TRIBUTE (Extrafine Inhaled Triple Therapy versus Dual
Bronchodilator Therapy in Chronic Obstructive Pulmonary Disease) study beclomethasone dipropionate $200 \mu \mathrm{g}$ BID (medium dose ICS) produced the same incidence of pneumonia compared to the LABA/LAMA treatment group. ${ }^{52}$ However, although the ICS fluticasone furoate and budesonide were both administered at medium doses in the FULFIL (Lung Function and Quality of Life Assessment in Chronic Obstructive Pulmonary Disease with Closed Triple Therapy) study, the incidence of pneumonia was $2.2 \%$ in the fluticasone furoate/umeclidinium/ vilanterol group and $0.8 \%$ in the budesonide/formoterol group. ${ }^{53}$ All this makes us believe that the risk of pneumonia is likely to be correlated not only with the equivalent dose of ICS, but also with the specific pharmacological characteristics of each molecule. ${ }^{37}$ It has been suggested that ICSs that remain longer in the airways induce greater local immunosuppression that may make patients more susceptible to respiratory infectious risk. ${ }^{54}$ Therefore, ICS should be prescribed carefully in patients with risk factors for pneumonia while considering the cumulative doses and subtypes of ICS. ${ }^{55}$

A detailed analysis of pneumonia data from replicate yearlong exacerbation studies suggested that risk factors for developing pneumonia are being a current smoker, being $\geq 55$ years of age, having a history of pneumonia, having a body mass index $<25 \mathrm{~kg} / \mathrm{m}^{2}$, and suffering from severe airflow limitation. ${ }^{56}$

However, Bourbeau et al reviewed evidence from RCTs showing the benefits of single-inhaler triple therapy and weighed these against the reported risk of pneumonia with ICS use and concluded that disease severity and history of exacerbations are strongly correlated with the risk of pneumonia, while ICS adds only a small additional risk. ${ }^{57}$ Furthermore, a joint analysis of the RCTs with a total of 53940 patients (31396 ICS and 22,544 nonICS) showed that pneumonia-related deaths are very rare in randomised trials. ${ }^{58}$ In fact, in this analysis, pneumonia mortality was 58/31,396 (1.84 cases per 1000) for ICS users, and 33/22,544 (1.46 cases per 1000) for non-users. Given the number of patients included, the clinical relevance of ICSs in pneumonia mortality is therefore doubtful.

\section{Mortality and Triple Therapy}

As COPD is the third leading cause of death worldwide, some recent studies have also focused on mortality, although mortality has never been a primary outcome in RCTs on triple therapy in COPD. ${ }^{59}$ A stratified safety 
pooled analysis of the time to death in the TRINITY (Single Inhaler Extrafine Triple Therapy versus LongActing Muscarinic Antagonist Therapy for Chronic Obstructive Pulmonary Disease), TRILOGY, and TRIBUTE RCTs showed a numerical, but not statistically significant reduction when comparing triple therapy vs LABA/LAMA treatments, although the risk of nonrespiratory fatal events was significantly reduced with ICS-containing treatments versus ICS-free treatments. ${ }^{60}$ In contrast, in the IMPACT ${ }^{61}$ and ETHOS ${ }^{62}$ RCTs, triple therapy reduced the risk of all-cause mortality compared with dual bronchodilation, although in the ETHOS study this was only observed when budesonide was present at a dose of $320 \mathrm{mcg}$ BID. ${ }^{62}$ However, it has been highlighted that the sample size in the ETHOS study was not selected based on considerations of power for mortality. ${ }^{63}$

It was hypothesized that survival gains obtainable with triple therapy compared with dual bronchodilation is related to the greater reduction in COPD exacerbations, which are known to increase the risk of myocardial infarction, stroke, and death. ${ }^{59}$ Conversely, a pooled analysis of data from over 6000 patients who participated in six Phase 3/4 RCTs, TONADO (A Randomised, Double-blind, Parallel Group Study to Assess the Efficacy and Safety of 52 Weeks of Once Daily Treatment of Orally Inhaled Tiotropium + Olodaterol Fixed Dose Combination $(2.5 \mu \mathrm{g} /$ $5 \mu \mathrm{g} ; 5 \mu \mathrm{g} / 5 \mu \mathrm{g})$ Delivered by the Respimat ${ }^{\circledR}$ Inhaler Compared With the Individual Components $(2.5 \mu \mathrm{g}$ and $5 \mu \mathrm{g}$ Tiotropium, $5 \mu \mathrm{g}$ Olodaterol) Delivered by the Respimat $^{\circledR}$ Inhaler in Patients With Chronic Obstructive Pulmonary Disease) 1/2, DYNAGITO (A Randomised, Double-blind, Active-controlled Parallel Group Study to Evaluate the Effect of 52 Weeks of Once Daily Treatment of Orally Inhaled Tiotropium + Olodaterol Fixed Dose Combination Compared With Tiotropium on COPD Exacerbation in Patients With Severe to Very Severe COPD), WISDOM (Withdrawal of Inhaled Steroids During Optimised bronchodilator Management), UPLIFT (The Understanding Potential Long-term Impacts on Function with Tiotropium) and TIOSPIR (Tiotropium Safety and Performance in Respimat), and received treatment with either ICS/LABA/LAMA or LABA/LAMA, showed no difference in mortality between triple therapy and LABA/LAMA in patients with moderate to very severe COPD and predominantly low risk of exacerbations. $^{64}$

\section{Triple Therapy and Step-Down Approach}

It has been proposed that patients in whom triple therapy is considered the first choice should be placed on maintenance therapy for at least the first 1-3 months but then step-down could be considered. ${ }^{49}$ However, step-down is always recommended if after 1-3 months patients do not report an improvement in symptoms.

It is important to establish whether and when it is possible to de-escalate triple therapy. The panel of expert COPD clinicians and researchers involved in the ATS clinical practical guideline wondered whether ICSs could be discontinued in COPD patients receiving triple therapy. ${ }^{14}$ The conclusion was that they could be discontinued if the patient has had no exacerbations in the last year. However, there is some doubt that de-escalation of triple therapy is an appropriate approach because each subsequent COPD exacerbation increases in intensity and significantly accelerates the course of the disease. ${ }^{48}$ It has been shown that the risk of a subsequent severe COPD exacerbation is tripled after the second severe exacerbation, and an extremely high mortality risk follows each severe COPD exacerbation. ${ }^{65}$

We conducted a meta-analysis on ICS withdrawal in COPD. ${ }^{66}$ Our findings were that this practice did not significantly increase the overall rate of COPD exacerbations, although a clinically important increase in the risk of severe exacerbations was found and the time to first exacerbation was significantly shorter in patients discontinuing ICS. However, discontinuation of ICS significantly impaired both lung function and quality of life, although not in a clinically important manner.

An official document reporting the European Respiratory Society recommendations regarding ICS withdrawal in patients with COPD concluded that in COPD patients without a history of frequent exacerbations ICS withdrawal is feasible (conditional recommendation which indicates that well-informed patients may make different choices regarding whether to have or not to have the intervention). ${ }^{67}$ However, the recommendations not to discontinue ICS in patients with $\geq 300$ eosinophils $\mu \mathrm{L}^{-1}$ in blood and to treat the patient with one or two long-acting bronchodilators if ICS is discontinued are strong.

\section{Triple Therapy in Real-World}

Patients treated in real life differ from those enrolled in studies and this is a cause for concern about the external 
validity of RCT data and the ability to broadly extrapolate these data to real-world patients. ${ }^{68}$

A real-life, single-centre, 24-week observational study suggested that triple therapy, when administered to patients with COPD and frequent exacerbations, can have a positive impact on dyspnoea and overall health status, as well as significantly decrease COPD exacerbations and improve airflow limitation and lung hyperinflation. ${ }^{69}$ The documentation of a significant improvement in the diffusing capacity of the lung for carbon monoxide $\left(\mathrm{DL}_{\mathrm{CO}}\right)$ in a substantial number of patients probably because of an improvement in small airway diameter due to reduced inflammation of bronchioles and alveoli is very interesting. Possibly, deflation resulting from triple therapy may have improved cardiac function, and this, together with increased alveolar ventilation, enhanced the perfusion/ventilation ratio, but this information is not available. ${ }^{68}$

In a real-world population of patients with COPD and a history of exacerbations, initiation of triple therapy was associated with a greater reduction in the risk of future exacerbations, acute respiratory events, and treatment failure than dual bronchodilation. ${ }^{70}$ The risk reduction of acute respiratory events with triple therapy was greater than with dual bronchodilation for patients with higher rates of previous exacerbations and higher blood eosinophil counts. However, there was no significant difference in the benefit of triple therapy by GOLD severity and risk group.

A multicentre prospective longitudinal study that was carried out in 12 hospitals in China showed that patients treated with LABA/LAMA had a higher incidence of severe exacerbations than with ICS/LABA/LAMA. ${ }^{71}$

In a British real-world setting (patients with COPD present in the UK's Clinical Practice Research Datalink) of triple-therapy initiators matched to LAMA/LABA initiators, the risk of COPD exacerbation was similar for each group over the first year of use; however, the triple therapy combination was more effective for patients with significant eosinophilia (blood eosinophil counts $>6 \%$ ) or frequent exacerbations (history of $\geq 2$ COPD exacerbations in the prior year). ${ }^{72}$

In contrast, the DACCORD (Die ambulante Versorgung mit langwirksamen Bronchodilatatoren: COPD-Register in Deutschland) study, a non-interventional, observational clinical study that recruited patients following COPD maintenance therapy initiation or change in maintenance therapy between or within therapeutic class, showed that within 1 year, fewer patients receiving dual bronchodilation exacerbated compared to those receiving triple therapy $(15.5 \%$ vs $26.6 \%){ }^{73}$ The highest rate of exacerbations was observed in patients who were on triple therapy before the study and remained on triple therapy. However, it must be mentioned that $>70 \%$ patients in DACCORD had no exacerbation 6 months prior to study entry.

In a "real-world" cohort of patients hospitalised for COPD in France, open triple therapy was not associated with better outcomes than dual therapy that, in any case, included free or fixed combinations of LABA/LAMA, LABA and ICS in FDCs or in free combinations, and free combinations of LAMA and ICS. ${ }^{74}$ Patients on triple therapy had higher healthcare resource use and COPDrelated costs than patients on dual therapy, mainly due to hospitalisations and, to a lesser extent, drug costs, which suggests that they were more severe than those on dual therapy. It should be noted that persistence rate was low in both groups. However, results of a recent meta-analysis indicate that triple therapy is more cost-effective than dual bronchodilation in patients with moderate to severe COPD because it provides more quality-adjusted life years and life years albeit at an additional cost. ${ }^{75}$ In any case, it must be mentioned in all pivotal RCTs there were fewer moderate to severe COPD exacerbations with triple therapy than dual bronchodilation, ${ }^{24}$ and as mentioned exacerbations leading to hospitalization contributes to a significant portion of the cost of total COPD expenditure. $^{76}$ This suggests that the higher acquisition cost of triple therapy would be offset by health service savings elsewhere.

There is an absolute need for further real-world studies that attempt to answer the question "does this intervention work under normal conditions?" to confirm the efficacy and safety of drugs that have been previously evaluated in RCTs. It has been suggested that the difference in the results of the studies conducted in the real world and, especially, the discrepancy between the conclusions of some of them and those obtained in the pivotal studies reflects the different patient populations in the studies in terms of previous exacerbations, ${ }^{77}$ and/or influence of pretreatment status. $^{78}$

\section{Conclusion}

The current available evidence from pivotal RCTs appears to be sufficient to identify triple therapy as an immediate choice in patients who present for the first time, and have severe airway obstruction $\left(\mathrm{FEV}_{1}<50 \%\right)$, are symptomatic, have had frequent $(\geq 2)$ moderate or severe exacerbations 
Table 3 When to Prefer Triple Therapy FDCs Over Dual Bronchodilation

Immediate choice in

- Patients who present for the first time, and have severe airway

obstruction $\left(\mathrm{FEV}_{1}<50 \%\right)$ and are symptomatic

- Patients who have had frequent $(\geq 2)$ moderate or severe

exacerbations ( $\geq 1$ hospitalisation) in the previous year

- Patients who have peripheral eosinophilia (>300 cells $\mu L^{-1}$ )

- Patients with significant lung function decline

- Patients discharged from hospital after a COPD exacerbation.

( $\geq 1$ hospitalisation) in the previous year, and have peripheral eosinophilia ( $>300$ cells $\left.\cdot \mu \mathrm{L}^{-1}\right)^{37,49}$ (Table 3 ). It must also be prescribed as first choice in in patients discharged from hospital after a COPD exacerbation ${ }^{48,49}$ and in those who present a significant decline in lung function. ${ }^{49}$ In all other cases, it is difficult to establish whether it is useful to go beyond dual bronchodilation because the available data are quite contradictory. ${ }^{39}$ It is likely that this inconsistency in the information from the various studies available may explain the prescribing behaviour of many doctors who do not adhere to guideline recommendations and strategies.

We strongly believe that those involved in writing guidelines or recommendations for the management of COPD should consider the discrepancy between the guidelines and everyday clinical practice, try to understand whether and why the guidelines do not reflect what is found in the real world, and then improve them. ${ }^{3}$

In our opinion, there is a need for further studies, especially in the real world to determine if and when the addition of an ICS to the LAMA/LABA combination is truly beneficial (Table 4). It is mandatory to establish whether and when it is effective in preventing exacerbations, ${ }^{1}$ considering the already mentioned fundamental differences in aetiology, severity, and biological substrate of COPDs exacerbations. ${ }^{31}$ We also believe that it is important to determine whether triple therapy is capable of truly inducing an additional clinical benefit over dual bronchodilation, independently of a preventive effect on COPD exacerbations, and to establish the value of this benefit. ${ }^{1,39}$ In addition, at a time of great contraction in healthcare investment, it is necessary to examine whether cost differences can support the use of triple therapy over LAMA/LABA combination therapy in real world across a variety of payer systems internationally.

In other words, even considering the well-known heterogeneity of COPD and the increasing emphasis on
Table 4 Future Research to Determine in Which Other Circumstances Triple Therapy is Preferable to Dual Bronchodilation

It must be determined

- Whether and when addition of an ICS to the LABA/LAMA

combination provides real additional clinical value, regardless of

a preventive effect on exacerbations;

-What kind of benefit it is;

- Which patients might benefit most from dual bronchodilation or triple therapy;

-Whether triple therapy may affect mortality in patients with COPD;

-Whether and when it is possible to de-escalate triple therapy

maintaining the patient on dual bronchodilation therapy;

- Whether the blood eosinophil count is a real biomarker to be used when choosing triple therapy or dual bronchodilation or the increase in the eosinophil count is just an epimarker of other biological processes or even is causally related in the pathogenesis of a patient's AECOPD risk;

- Whether LAMA/LABA combination therapy is preferred over triple therapy also because of the cost differences between the two treatments in real-life.

personalised medicine, it will be important to define which patients might benefit most from the different drug combinations (ICS/LABA/LAMA/ vs LABA/LAMA vs ICS/LABA). This requires appropriately designed studies and analysis plans to investigate the relative advantages and disadvantages of these different combinations in different subgroups of COPD patients defined by clinical criteria, preferably in combination with validated biomarkers. ${ }^{79}$

Unfortunately, we have not yet understood whether the eosinophil is causally related in the pathogenesis of a patient's AECOPD risk, or whether it is just an epimarker of other biological processes that predispose patients to increased exacerbation risk.

Consequently, switching from dual bronchodilation to triple therapy considering the blood eosinophil count as a valid biomarker to predict the risk of exacerbations and the clinical response to ICS cannot yet be considered an established practice. In fact, evidence demonstrating a better response to ICS with increased blood eosinophils comes from post hoc, pre-specified secondary and data modelling analyses, whereas no consistent relationship has been found in observational studies. ${ }^{1,80}$ Moreover, neither the Food and Drug Administration nor the European Medicines Agency recommend the use of blood eosinophils in patients with COPD. ${ }^{45}$

However, we would like to reiterate the concept that each LABA/LAMA combination and the addition of each specific 
ICS have a unique efficacy/safety profile that must be considered for individualised therapy in COPD. Unfortunately, the treatment algorithms recommended in COPD guidelines/ strategies always refer to classes of drugs to be used rather than individual molecules with unique pharmacological characteristics. They do not consider that the pharmacodynamics and pharmacokinetics of any LABA, LAMA or ICS included in a specific FDC may make this combination more effective than others of the same type and even different types of FDC, regardless of what is expected from the application of the COPD guideline/strategy algorithms. We firmly believe that individual molecules, regardless of whether they are bronchodilators or ICS, should be chosen for their pharmacological characteristics rather than for their belonging to a specific drug class. This obviously also applies to all combinations. ${ }^{81}$

\section{Authorship}

All authors made substantial contributions to conception and design, acquisition of data, or analysis and interpretation of data; took part in drafting the article or revising it critically for important intellectual content; agreed to submit to the current journal; gave final approval of the version to be published; and agree to be accountable for all aspects of the work.

\section{Funding}

There is no funding to report.

\section{Disclosure}

M Cazzola was a faculty member and advisor in scientific meetings sponsored by Abdi Ibrahim, Almirall, AstraZeneca, Boehringer Ingelheim, Chiesi Farmaceutici, Cipla, Edmond Pharma, GlaxoSmithKline, Glenmark, Lallemand, Menarini Group, Mundipharma, Novartis, Pfizer, Teva, Verona Pharma, and Zambon, and is or was a consultant to ABC Farmaceutici, AstraZeneca, Chiesi Farmaceutici, Edmond Pharma, Lallemand, Novartis, Ockham Biotech, VeronaPharma, and Zambon.

P Rogliani reported grants and personal fees from Almirall, AstraZeneca, Biofutura, Boehringer Ingelheim, Chiesi Farmaceutici, GlaxoSmithKline, Menarini Group, Mundipharma, and Novartis, and participated as a lecturer and advisor in scientific meetings sponsored by Almirall, AstraZeneca, Biofutura, Boehringer Ingelheim, Chiesi Farmaceutici, Edmond Pharma, GlaxoSmithKline, Menarini Group, Mundipharma, and Novartis. Almirall, Boehringer Ingelheim, Chiesi Farmaceutici, Novartis, and Zambon funded her department.
R Laitano has no potential conflict of interest.

L Calzetta participated as an advisor in scientific meetings sponsored by Boehringer Ingelheim and Novartis, received non-financial support from AstraZeneca, a research grant partially funded by Chiesi Farmaceutici, Boehringer Ingelheim, Novartis, and Almirall, and is or was a consultant to ABC Farmaceutici, Recipharm, Zambon, Verona Pharma and Ockham Biotech. Almirall, Boehringer Ingelheim, Chiesi Farmaceutici, Novartis and Zambon funded his department.

MG Matera participated as a faculty member and advisor in scientific meetings sponsored by ABC Farmaceutici, Almirall, AstraZeneca, Chiesi Farmaceutici, GlaxoSmithKline, and Novartis, and was a consultant to Chiesi Farmaceutici, and GlaxoSmithKline. GlaxoSmithKline, and Novartis funded her department.

The authors have no other relevant affiliations or financial involvement with any organization or entity with a financial interest in or financial conflict with the subject matter or materials discussed in the manuscript apart from those disclosed.

\section{References}

1. Calzetta L, Matera MG, Rogliani P, Cazzola M. The role of triple therapy in the management of COPD. Expert Rev Clin Pharmacol. 2020;13(8):865-874. doi:10.1080/17512433.2020.1787830

2. Grewe FA, Sievi NA, Bradicich M, et al. Compliance of pharmacotherapy with GOLD guidelines: a longitudinal study in patients with COPD. Int J Chron Obstruct Pulmon Dis. 2020;15:627-635. doi:10.2147/COPD.S240444

3. Maniscalco M, Martucci M, Fuschillo S, de Felice A, D’Anna SE, Cazzola M. A case scenario study on adherence to COPD GOLD recommendations by general practitioners in a rural area of southern Italy: the "progetto PADRE". Respir Med. 2020;170:105985. doi:10. 1016/j.rmed.2020.105985

4. Brusselle G, Price D, Gruffydd-Jones K, et al. The inevitable drift to triple therapy in COPD: an analysis of prescribing pathways in the UK. Int J Chron Obstruct Pulmon Dis. 2015;10:2207-2217. doi:10. 2147/COPD.S91694

5. Simeone JC, Luthra R, Kaila S, et al. Initiation of triple therapy maintenance treatment among patients with COPD in the US. Int J Chron Obstruct Pulmon Dis. 2016;12:73-83. doi:10.2147/COPD. S122013

6. Palmiotti GA, Lacedonia D, Liotino V, et al. Adherence to GOLD guidelines in real-life COPD management in the Puglia region of Italy. Int J Chron Obstruct Pulmon Dis. 2018;13:2455-2462. doi:10.2147/ COPD.S157779

7. Di Marco F, Santus P, Terraneo S, et al. Characteristics of newly diagnosed COPD patients treated with triple inhaled therapy by general practitioners: a real world Italian study. NPJ Prim Care Respir Med. 2017;27(1):51. doi:10.1038/s41533-017-0051-9

8. Larsson K, Ekberg-Jansson A, Stridsman C, Hanno M, Vanfleteren LEGW. Adherence to treatment recommendations for chronic obstructive pulmonary disease - Results from the Swedish National Airway Register. Int $J$ Chron Obstruct Pulmon Dis. 2021;16:909-918. doi:10.2147/COPD.S300299 
9. Cazzola M, Matera MG. Triple combinations in chronic obstructive pulmonary disease - is three better than two? Expert Opin Pharmacother. 2014;15(17):2475-2478. doi:10.1517/14656566.20 14.972367

10. Schabert V, Shah S, Holmgren U, Cabrera C. Prescribing pathways to triple therapy in patients with chronic obstructive pulmonary disease in the United States. Ther Adv Respir Dis. 2021;15:1753 4666211001018. doi:10.1177/17534666211001018

11. Monteagudo M, Barrecheguren M, Solntseva I, et al. Clinical characteristics and factors associated with triple therapy use in newly diagnosed patients with COPD. NPJ Prim Care Respir Med. 2021;31 (1):16. doi:10.1038/s41533-021-00227-x

12. Quint JK, O'Leary C, Venerus A, et al. Prescribing pathways to triple therapy: a multi-country, retrospective observational study of adult patients with chronic obstructive pulmonary disease. Pulm Ther. 2020;6(2):333-350. doi:10.1007/s41030-020-00132-7

13. Singh D, Agusti A, Anzueto A, et al. Global strategy for the diagnosis, management, and prevention of chronic obstructive lung disease: the GOLD science committee report 2019. Eur Respir J. 2019;53(5):1900164. doi:10.1183/13993003.00164-2019

14. Nici L, Mammen MJ, Charbek E, et al. Pharmacologic management of chronic obstructive pulmonary disease. An official American Thoracic Society clinical practice guideline. Am J Respir Crit Care Med. 2020;201(9):e56-e69. doi:10.1164/rccm.202003-0625ST

15. Bourbeau J, Bhutani M, Hernandez P, et al. Canadian Thoracic Society Clinical Practice Guideline on pharmacotherapy in patients with COPD - 2019 update of evidence. Can J Respir Crit Care Sleep Med. 2019;3(4):210-232.

16. Calzetta L, Matera MG, Cazzola M. Pharmacological interaction between LABAs and LAMAs in the airways: optimizing synergy. Eur J Pharmacol. 2015;761:168-173. doi:10.1016/j.ejphar.2015.05.020

17. Matera MG, Page CP, Calzetta L, Rogliani P, Cazzola M. Pharmacology and Therapeutics of Bronchodilators Revisited. Pharmacol Rev. 2020;72(1):218-252. doi:10.1124/pr.119.018150

18. Rogliani P, Matera MG, Facciolo F, Page C, Cazzola M, Calzetta L. Beclomethasone dipropionate, formoterol fumarate and glycopyrronium bromide: synergy of triple combination therapy on human airway smooth muscle ex vivo. $B r \quad J$ Pharmacol. 2020;177 (5):1150-1163. doi:10.1111/bph.14909

19. Rogliani P, Ritondo LB, Zerillo B, Matera MG, Calzetta L. Drug interaction and chronic obstructive respiratory disorders. Curr Res Pharmacol Drug Discov. 2021;2:100009. doi:10.1016/j.crphar.2020.100009

20. Rogliani P, Ora J, Girolami A, et al. Ceiling effect of beclomethasone/formoterol/glycopyrronium triple fixed-dose combination in COPD: a translational bench-to-bedside study. Pulm Pharmacol Ther. 2021;69:102050.

21. Zheng Y, Zhu J, Liu Y, et al. Triple therapy in the management of chronic obstructive pulmonary disease: systematic review and meta-analysis. BMJ. 2018;363:k4388. doi:10.1136/bmj.k4388

22. Cazzola M, Rogliani P, Calzetta L, Matera MG. Triple therapy versus single and dual long-acting bronchodilator therapy in COPD: a systematic review and meta-analysis. Eur Respir J. 2018;52 (6):1801586. doi:10.1183/13993003.01586-2018

23. Lai CC, Chen CH, Lin CYH, Wang CY, Wang YH. The effects of single inhaler triple therapy vs single inhaler dual therapy or separate triple therapy for the management of chronic obstructive pulmonary disease: a systematic review and meta-analysis of randomized controlled trials. Int J Chron Obstruct Pulmon Dis. 2019;14:1539-1548. doi:10.2147/COPD.S200846

24. Calzetta L, Cazzola M, Matera MG, Rogliani P. Adding a LAMA to ICS/LABA therapy: a meta-analysis of triple combination therapy in COPD. Chest. 2019;155(4):758-770. doi:10.1016/j.chest.2018.12. 016
25. Mammen MJ, Lloyd DR, Kumar S, et al. Triple therapy versus dual or monotherapy with long-acting bronchodilators for chronic obstructive pulmonary disease. A systematic review and meta-analysis. Ann Am Thorac Soc. 2020;17(10):1308-1318. doi:10.1513/AnnalsATS. 202001-023OC

26. Koarai A, Yamada M, Ichikawa T, Fujino N, Kawayama T, Sugiura H. Triple versus LAMA/LABA combination therapy for patients with COPD: a systematic review and meta-analysis. Respir Res. 2021;22(1):183. doi:10.1186/s12931-021-01777-x

27. Long $\mathrm{H}, \mathrm{Xu} \mathrm{H}$, Janssens JP, Guo Y. Single-inhaler triple vs single-inhaler dual therapy in patients with chronic obstructive pulmonary disease: a meta-analysis of randomized control trials. Respir Res. 2021;22(1):209. doi:10.1186/s12931-021-01794-w

28. Cazzola M, Calzetta L, Rogliani P, Matera MG. Triple therapy versus dual bronchodilation and inhaled corticosteroids/long-acting $\beta$-agonists in COPD: accumulating evidence from network meta-analyses. Pulm Ther. 2019;5(2):117-126. doi:10.1007/s41030-019-00102-8

29. Calzetta L, Ritondo BL, de Marco P, Cazzola M, Rogliani P. Evaluating triple ICS/LABA/LAMA therapies for COPD patients: a network meta-analysis of ETHOS, KRONOS, IMPACT, and TRILOGY studies. Expert Rev Respir Med. 2021;15(1):143-152. doi:10.1080/17476348.2020.1816830

30. Daley-Yates PT. Inhaled corticosteroids: potency, dose equivalence and therapeutic index. Br J Clin Pharmacol. 2015;80(3):372-380. doi:10.1111/bcp.12637

31. Matera MG, Rinaldi B, Calzetta L, Rogliani P, Cazzola M. Pharmacokinetics and pharmacodynamics of inhaled corticosteroids for asthma treatment. Pulm Pharmacol Ther. 2019;58:101828. doi:10.1016/j.pupt.2019.101828

32. Cazzola M, Page CP, Rogliani P, Matera MG. $\beta_{2}$-agonist therapy in lung disease. Am J Respir Crit Care Med. 2013;187(7):690-696. doi:10.1164/rccm.201209-1739PP

33. Cazzola M, Matera MG. Bronchodilators for airway disease. In: Janes SM, editor. Encyclopedia of Respiratory Medicine. Vol. 2. Elsevier, Academic Press; 2022:712-728.

34. Matera MG, Belardo C, Rinaldi M, Rinaldi B, Cazzola M. Emerging muscarinic receptor antagonists for the treatment of asthma. Expert Opin Emerg Drugs. 2020;25(2):123-130. doi:10.1080/14728214. 2020.1758059

35. Rogliani P, Calzetta L, Ora J, et al. Pharmacological assessment of the onset of action of Aclidinium and glycopyrronium versus tiotropium in COPD patients and human isolated bronchi. Eur J Pharmacol. 2015;761:383-390. doi:10.1016/j.ejphar.2015.04.042

36. Bourdin A, Molinari N, Ferguson GT, et al. Efficacy and safety of budesonide/glycopyrronium/formoterol fumarate versus other triple combinations in COPD: a systematic literature review and network meta-analysis. Adv Ther. 2021;38(6):3089-3112. doi:10.1007/s12 325-021-01703-z

37. Ritondo BL, Puxeddu E, Calzetta L, Cazzola M, Rogliani P. Efficacy and safety of triple combination therapy for treating chronic obstructive pulmonary disease: an expert review. Expert Opin Pharmacother. 2021;22(5):611-620. doi:10.1080/14656566.2020.1845314

38. Agusti A, Fabbri LM, Singh D, et al. Inhaled corticosteroids in COPD: friend or foe? Eur Respir J. 2018;52(6):1801219. doi:10. 1183/13993003.01219-2018

39. Cazzola M, Rogliani P, Stolz D, Matera MG. Pharmacological treatment and current controversies in COPD. F1000Res. 2019;8: F1000Faculty Rev-1533. doi:10.12688/f1000research.19811.1

40. Stolz D, Miravitlles M. The right treatment for the right patient with COPD: lessons from the IMPACT trial. Eur Respir J. 2020;55 (5):2000881. doi:10.1183/13993003.00881-2020

41. Cazzola M, MacNee W, Martinez FJ, et al. Outcomes for COPD pharmacological trials: from lung function to biomarkers. Eur Respir J. 2008;31(2):416-469. doi:10.1183/09031936.00099306 
42. Cazzola M, Calzetta L, Rogliani P, Matera MG. The challenges of precision medicine in COPD. Mol Diagn Ther. 2017;21(4):345-355. doi:10.1007/s40291-017-0266-z

43. Bafadhel M, McKenna S, Terry S, et al. Acute exacerbations of chronic obstructive pulmonary disease: identification of biologic clusters and their biomarkers. Am J Respir Crit Care Med. 2011;184(6):662-671. doi:10.1164/rccm.201104-0597OC

44. Harries TH, Rowland V, Corrigan CJ, et al. Blood eosinophil count, a marker of inhaled corticosteroid effectiveness in preventing COPD exacerbations in post-hoc RCT and observational studies: systematic review and meta-analysis. Respir Res. 2020;21(1):3. doi:10.1186/ s12931-019-1268-7

45. Cazzola M, Puxeddu E, Ora J, Rogliani P. Evolving concepts in chronic obstructive pulmonary disease blood-based biomarkers. Mol Diagn Ther. 2019;23(5):603-614. doi:10.1007/s40291-019-00413-1

46. Wilkerson EM, Johansson MW, Hebert AS, et al. The peripheral blood eosinophil proteome. J Proteome Res. 2016;15(5):1524-1533. doi:10.1021/acs.jproteome.6b00006

47. O'Sullivan JA, Bochner BS. Eosinophils and eosinophil-associated diseases: an update. J Allergy Clin Immunol. 2018;141(2):505-517. doi:10.1016/j.jaci.2017.09.022

48. Cazzola M, Rogliani P, Matera MG. Escalation and de-escalation of therapy in COPD: myths, realities and perspectives. Drugs. 2015;75 (14):1575-1585. doi:10.1007/s40265-015-0450-6

49. Vanfleteren LEGW, Ullman A, Nordenson A, Andersson A, Andelid K, Fabbri LM. Triple therapy (ICS/LABA/LAMA) in COPD: thinking out of the box. ERJ Open Res. 2019;5 (1):00185-2018. doi:10.1183/23120541.00185-2018

50. Finney L, Berry M, Singanayagam A, Elkin SL, Johnston SL, Mallia P. Inhaled corticosteroids and pneumonia in chronic obstructive pulmonary disease. Lancet Respir Med. 2014;2(11):919-932. doi:10.1016/S2213-2600(14)70169-9

51. Rabe KF, Martinez FJ, Ferguson GT, et al. Triple inhaled therapy at two glucocorticoid doses in moderate-to-very-severe COPD. $N$ Engl $J$ Med. 2020;383(1):35-48. doi:10.1056/NEJMoa1916046

52. Papi A, Vestbo J, Fabbri L, et al. Extrafine inhaled triple therapy versus dual bronchodilator therapy in chronic obstructive pulmonary disease (TRIBUTE): a double-blind, parallel group, randomised controlled trial. Lancet. 2018;391(10125):1076-1084. doi:10.1016/ S0140-6736(18)30206-X

53. Lipson DA, Barnacle H, Birk R, et al. FULFIL trial: once-daily triple therapy for patients with chronic obstructive pulmonary disease. Am J Respir Crit Care Med. 2017;196(4):438-446. doi:10.1164/ rccm.201703-0449OC

54. Janson C, Stratelis G, Miller-Larsson A, Harrison TW, Larsson K. Scientific rationale for the possible inhaled corticosteroid intraclass difference in the risk of pneumonia in COPD. Int $J$ Chron Obstruct Pulmon Dis. 2017;12:3055-3064. doi:10.2147/COPD. S143656

55. Lee JH, Park YH, Kang DR, et al. Risk of pneumonia associated with inhaled corticosteroid in patients with chronic obstructive pulmonary disease: a Korean population-based study. Int J Chron Obstruct Pulmon Dis. 2020;15:3397-3406. doi:10.2147/COPD.S286149

56. Crim C, Dransfield MT, Bourbeau J, et al. Pneumonia risk with inhaled fluticasone furoate and vilanterol compared with vilanterol alone in patients with COPD. Ann Am Thorac Soc. 2015;12(1):27-34. doi:10.1513/AnnalsATS.201409-413OC

57. Bourbeau J, Bafadhel M, Barnes NC, et al. Benefit/risk profile of single-inhaler triple therapy in COPD. Int J Chron Obstruct Pulmon Dis. 2021;16:499-517. doi:10.2147/COPD.S291967

58. Almagro P, Martinez-Camblor P, Soriano JB. Inhaled corticosteroids and pneumonia mortality in COPD patients. Eur Respir J. 2019;54 (3):1901035. doi:10.1183/13993003.01035-2019

59. Andreas S, Taube C. Inhaled therapy reduces COPD mortality. ERJ Open Res. 2020;6(4):00634-2020. doi:10.1183/23120541.006342020
60. Vestbo J, Fabbri L, Papi A, et al. Inhaled corticosteroid containing combinations and mortality in COPD. Eur Respir J. 2018;52 (6):1801230. doi:10.1183/13993003.01230-2018

61. Halpin DMG, Criner GJ, Dransfield MT, et al. Triple versus dual combination therapy in chronic obstructive pulmonary disease in Asian countries: analysis of the IMPACT trial. Pulm Ther. 2021;7 (1):101-118. doi:10.1007/s41030-020-00136-3

62. Martinez FJ, Rabe KF, Ferguson GT, et al. Reduced all-cause mortality in the ETHOS trial of budesonide/glycopyrrolate/formoterol for chronic obstructive pulmonary disease. A randomized, double-blind, multicenter, parallel-group study. Am J Respir Crit Care Med. 2021;203(5):553-564. doi:10.1164/rccm.202006-2618OC

63. Rogliani P, Calzetta L. Mortality in ETHOS: a Question of "power". Am J Respir Crit Care Med. 2021;203(7):926-927. doi:10.1164/ rccm.202012-4328LE

64. Miravitlles M, Calverley PMA, Verhamme K, et al. A pooled analysis of mortality in patients with COPD receiving triple therapy versus dual bronchodilation (abstract). Am J Respir Crit Care Med. 2021; 203:A2251.

65. Suissa S, Dell'Aniello S, Ernst P. Long-term natural history of chronic obstructive pulmonary disease: severe exacerbations and mortality. Thorax. 2012;67(11):957-963. doi:10.1136/thoraxjnl2011-201518

66. Calzetta L, Matera MG, Braido F, et al. Withdrawal of inhaled corticosteroids in COPD: a meta-analysis. Pulm Pharmacol Ther. 2017;45:148-158. doi:10.1016/j.pupt.2017.06.002

67. Chalmers JD, Laska IF, Franssen FME, et al. Withdrawal of inhaled corticosteroids in COPD: a European Respiratory Society guideline. Eur Respir J. 2020;55(6):2000351. doi:10.1183/13993003.00351-2020

68. Cazzola M, Celli B. Triple therapy is also effective in real-world when used in chronic obstructive pulmonary disease patients who are frequent exacerbators. Respiration. 2021;100(2):93-95. doi:10.1159/ 000512728

69. Pelaia C, Procopio G, Deodato MR, et al. Real-life clinical and functional effects of fluticasone furoate/umeclidinium/vilanterol-combined triple therapy in patients with chronic obstructive pulmonary disease. Respiration. 2021;100(2):127-134. doi:10.1159/00051 2064

70. Voorham J, Corradi M, Papi A, et al. Comparative effectiveness of triple therapy versus dual bronchodilation in COPD. ERJ Open Res. 2019;5(3):00106-2019. doi:10.1183/23120541.00106-2019

71. Cheng W, Duan J, Zhou A, et al. Real-world effectiveness of inhalation therapy among patients with symptomatic COPD in China: a multicenter prospective study. Front Pharmacol. 2021;12:753653. doi:10.3389/fphar.2021.753653

72. Suissa S, Dell-Aniello S, Ernst P. Comparative effects of LAMA-LABA-ICS vs LAMA LABA for COPD: cohort study in real-world clinical practice. Chest. 2020;157(4):846-855. doi:10. 1016/j.chest.2019.11.007

73. Buhl R, Criée CP, Kardos P, et al. Dual bronchodilation vs triple therapy in the "real-life" COPD DACCORD study. Int J Chron Obstruct Pulmon Dis. 2018;13:2557-2568. doi:10.2147/COPD. S169958

74. Dalon F, Roche N, Belhassen M, et al. Dual versus triple therapy in patients hospitalized for COPD in France: a claims data study. Int J Chron Obstruct Pulmon Dis. 2019;14:1839-1854. doi:10.21 47/COPD.S214061

75. Syed AA, Sharma GN, Shrivastav B, Mohd AN. Meta-analysis of cost-effectiveness of three-drug therapy versus two-drug therapy in chronic obstructive pulmonary disease patients. J Appl Pharm Sci. 2021;11(09):129-138.

76. Gutiérrez Villegas C, Paz-Zulueta M, Herrero-Montes M, Parás-Bravo P, Madrazo Pérez M. Cost analysis of chronic obstructive pulmonary disease (COPD): a systematic review. Health Econ Rev. 2021;11(1):31. doi:10.1186/s13561-02100329-9 
77. Buhl R, Dreher M, Korn S, et al. A non-Interventional study of tiotropium/olodaterol versus any triple combination therapy for chronic obstructive pulmonary disease: the EVELUT ${ }^{\circledR}$ study protocol. Int J Chron Obstruct Pulmon Dis. 2020;15:2601-2608. doi:10.2147/COPD.S262746

78. Huang WC, Chen CY, Liao WC, et al. A real world study to assess the effectiveness of switching to once daily closed triple therapy from mono/dual combination or open triple therapy in patients with chronic obstructive pulmonary disease. Int J Chron Obstruct Pulmon Dis. 2021;16:1555-1568. doi:10.2147/COPD.S308911

79. Tashkin DP, Taube C. Triple therapy for chronic obstructive pulmonary disease management. Are our expectations fulfilled? Am J Respir Crit Care Med. 2017;196(4):402-404. doi:10.1164/rccm.201704-0760ED

80. Lopez-Campos JL, Carrasco-Hernandez L, Quintana-Gallego E, et al. Triple therapy for COPD: a crude analysis from a systematic review of the evidence. Ther Adv Respir Dis. 2019;13:1753466619885522. doi:10.1177/1753466619885522
81. Cazzola M, Matera MG. An obvious paradigm: choosing bronchodilators and inhaled corticosteroids for their pharmacologic characteristics. Chest. 2021;160(4):1157-1159. doi:10.1016/j.chest.2021.06.025

82. Lipson DA, Barnhart F, Brealey N, et al. Once-daily single-inhaler triple versus dual therapy in patients with COPD. $N$ Engl J Med. 2018;378(18):1671-1680. doi:10.1056/NEJMoa1713901

83. Ferguson GT, Rabe KF, Martinez FJ, et al. Triple therapy with budesonide/glycopyrrolate/formoterol fumarate with co-suspension delivery technology versus dual therapies in chronic obstructive pulmonary disease (KRONOS): a double-blind, parallel-group, multicentre, phase 3 randomised controlled trial. Lancet Respir Med. 2018;6(10):747-758. doi:10.1016/S2213-2600(18)30327-8

\section{Publish your work in this journal}

The International Journal of COPD is an international, peer-reviewed journal of therapeutics and pharmacology focusing on concise rapid reporting of clinical studies and reviews in COPD. Special focus is given to the pathophysiological processes underlying the disease, intervention programs, patient focused education, and self management protocols. This journal is indexed on PubMed Central, MedLine and CAS. The manuscript management system is completely online and includes a very quick and fair peer-review system, which is all easy to use. Visit http://www.dovepress.com/testimonials.php to read real quotes from published authors. 